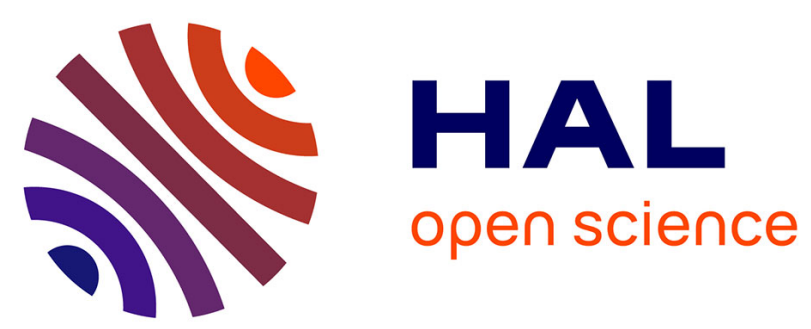

\title{
Deracemization in a complex quaternary system with a second- order asymmetric transformation using phase diagram studies
}

Ryusei Oketani, Francesco Marin, Paul Tinnemans, Marine Hoquante, Anne Laurent, Clément Brandel, Pascal Cardinaël, Hugo Meekes, Elias Vlieg, Yves Geerts, et al.

\section{To cite this version:}

Ryusei Oketani, Francesco Marin, Paul Tinnemans, Marine Hoquante, Anne Laurent, et al.. Deracemization in a complex quaternary system with a second- order asymmetric transformation using phase diagram studies. Chemistry - A European Journal, 2019, 25 (61), pp.13890-13898. 10.1002/chem.201903338 . hal-02276778

\section{HAL Id: hal-02276778}

\section{https://hal-normandie-univ.archives-ouvertes.fr/hal-02276778}

Submitted on 3 Sep 2019

HAL is a multi-disciplinary open access archive for the deposit and dissemination of scientific research documents, whether they are published or not. The documents may come from teaching and research institutions in France or abroad, or from public or private research centers.
L'archive ouverte pluridisciplinaire HAL, est destinée au dépôt et à la diffusion de documents scientifiques de niveau recherche, publiés ou non, émanant des établissements d'enseignement et de recherche français ou étrangers, des laboratoires publics ou privés. 


\title{
Deracemization in a complex quaternary system with a second- order asymmetric transformation using phase diagram studies
}

\author{
Ryusei Oketani, ${ }^{[a]}$ Francesco Marin, ${ }^{[b]}$ Paul Tinnemans, ${ }^{[c]}$ Marine Hoquante, ${ }^{\left[{ }^{[a]}\right.}$ Anne Laurent, ${ }^{[b]}$ Clément \\ Brandel, ${ }^{[a]}$ Pascal Cardinael, ${ }^{[a]}$ Hugo Meekes, ${ }^{[c]}$ Elias Vlieg, ${ }^{[c]}$ Yves Geerts, ${ }^{[b]}$ Gérard Coquerel ${ }^{*[a]}$
}

\begin{abstract}
We report herein, a productive deracemization process based on a quaternary phase diagram study of a naphthamide derivative. New racemic compounds of an atropisomeric naphthamide derivative were discovered, and a quarternay phase diagram was constructed which indicated that four solids were stable in a methanol/ $\mathrm{H}_{2} \mathrm{O}$ solution. Based on the heterogeneous equilibria study showing the stable domain of the conglomerate, a second-order asymmetric transformation was achieved up to $97 \%$ ee. Further, the methodology showcases the chiral separation of a stable racemic compound forming system and does not suffer from any typical limitations of deracemization, although application is still limited to conglomerate forming systems. We anticipate that this demonstration will serve as a fundamental model for the design of sophisticated chiral separation processes.
\end{abstract}

\section{Introduction}

Chirality or asymmetry is a fundamental property and has critical importance in many avenues of nature, particularly in biology and pharmaceutics. Indeed, the human body consists of a large variety of chiral amino acids and sugar molecules, and the availability of chiral separation techniques is paramount to enable studies relating to the biological function and activity of chiral molecules. Access to the desired polymorph and enantiomer of the particular compound is a critical issue in the field of pharmaceutical chemistry owing to the difference of bioavailability and bioactivity among polymorphs and enantiomers. Among the 42 drugs of chemical entities approved by the Food and Drug Administration (FDA) in 2018, 25 molecules contain a chiral center ${ }^{[1,2]}$, and over $80 \%$ of the active pharmaceutical ingredients (APIs) exhibit polymorphism or solvate formation ${ }^{[3,4]}$ and may show differences in physical properties, which makes chiral separation and polymorph control vital aspects of drug development. Classical chiral resolution techniques such as chemical transformation mediated diastereomeric resolutions are robust and reliable approaches to prepare enantiomerically pure materials and are preferentially used in industrial chemistry. However, in such approaches, the undesired enantiomer, which constitutes half of the product is wasted or needs to be recycled.

[a] R. Oketani, M. Hoquante, Dr. C. Blandel, Prof. Dr. P.Cardinael, Prof. Dr. G. Coquerel

Université de Rouen Normandie, UFR des Sciences et Techniques, Laboratoire SMS-EA3233, Place Emile Blondel, 76821 Mont-SaintAignan, France

E-mail: gerard.coquerel@univ-rouen.fr

[b] F. Marin, A. Laurent, Prof. Dr. Geerts

Laboratoire de Chimie des Polymères, Faculté des Sciences,

Université libre de Bruxelles (ULB), Boulevard du Triomphe, 1050

Brussels, Belgium

[c] Dr. P. Tinnemans, Dr. H. Meekes, Prof. Dr. E. Vlieg

Radboud University, Institute for Molecules and Materials,

Heyendaalseweg 135, 6525 AJ Nijmegen, The Netherlands
To reduce such waste and improve productivity, chiral separation by deracemization, an approach which combines racemization with crystallization, has been the subject of intense studies.

Viedma ripening $(\mathrm{VR})^{[5-9]}$ and temperature cycle induced deracemization (TCID) $)^{[10-15]}$ are key approaches to deracemization. and are being actively studied. We recently reported that second-order asymmetric transformation (SOAT $)^{[16]}$, a combination of preferential crystallization $(P C)$ and racemization, could achieve relatively high process productivity compared to TCID due to short process time. In this report, we use a SOAT based approach for an efficient chiral resolution.

Phase diagrams are important tools for understanding and controlling the crystallization. Indeed, the construction of a phase diagram is essential for rationally: (i) determining appropriate crystallization conditions of molecules exhibiting multiple solid phases, (ii) assessing the thermodynamic stability of solid phases, (iii) controlling the supersaturation. ${ }^{[17-19]}$ Recently, our group demonstrated that PC could be applied on a metastable conglomerate of diprophylline, which crystallizes in multiple crystal forms depending on the conditions. ${ }^{[20]}$ However, the utility of such an approach using phase diagram investigations for deracemization has not been reported yet. While deracemization is a well-developed chiral resolution technique, it still suffers from limitations. For example, it is applicable only to conglomerate forming systems, i.e. $5-10 \%$ of the racemic crystals. ${ }^{[21]}$ Since racemization of the substrate is a requirement for the deracemization process, the gap of two thermodynamic equilibrium states of the process must be tuned to design reaction conditions for an efficient deracemization. For advanced industrial applications, the availability of model studies is crucial in order to facilitate process modeling. The present work aims at serving as a model study for the use of a phase diagram based approach for deracemization of molecules that exhibit a complex solid phase landscape.

In the present study, we characterized two new solid phases of atropisomeric naphthamide 1, shown in Figure 1, using SC-XRD, DSC, and XRPD measurements and constructed the quaternary phase diagram of $\mathbf{1}$ in a mixture of methanol $(\mathrm{MeOH})$ and water $\left(\mathrm{H}_{2} \mathrm{O}\right)$ using XRPD and solubility measurements. Further, we studied the impact of temperature on the racemic isoplethal section. Based on the conditions obtained from the phase diagram study, we successfully performed the chiral resolution of 1 by SOAT in a $\mathrm{MeOH} / \mathrm{H}_{2} \mathrm{O}$ solution and achieved up to $97 \%$ ee and a productivity of $6.5 \mathrm{~g} \mathrm{~h}^{-1} \mathrm{~L}^{-1}$ 


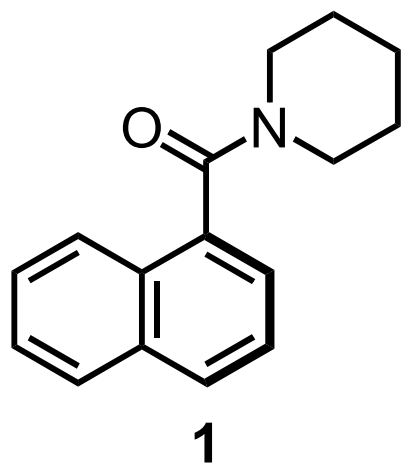

Figure 1. Chemical structure of atropisomeric naphthamide 1.

\section{Results and Discussion}

\subsection{Preparation and characterization of $\mathrm{C}$, Rac, and Me}

In 2005, Sakamoto et al. reported the crystal structure of the first form of 1 and designated it as $C^{[22]}$ which can be prepared from solutions of 1 in many conventional solvents, except in $\mathrm{MeOH}$, by slow evaporation. The space group of $C$ is $P 2{ }_{1} 2_{1} 2_{1}$, and the crystals form a conglomerate. Racemic compound, Rac, could be obtained in the first crop by cooling crystallization from a mixture of chloroform and heptane $(1 / 1, \mathrm{v} / \mathrm{v})$. Indeed, after the collection of Rac by filtration, only $\mathrm{C}$ crystallized from the filtrate. Rac can also be prepared by suspending any crystal form in a mixture of $\mathrm{MeOH} / \mathrm{H}_{2} \mathrm{O}(70 / 30, \mathrm{v} / \mathrm{v})$ at $15^{\circ} \mathrm{C}$. As the melting point of Rac is lower by $12{ }^{\circ} \mathrm{C}$ than that of the racemic mixture of $\mathrm{C}$, it could be considered as a less stable phase than $\mathrm{C}$ at high temperature in the binary system.

Further, comparison between the enthalpy of fusion $\left(\Delta H_{\text {fus }}\right)$ also supports the order of stability. $\mathrm{A}<1-1>$ racemic $\mathrm{MeOH}$ solvate (hereafter Me) could also be prepared. The deposited crystals appeared highly transparent in the solution, and after filtration, the surface of the crystals desolvated and turned to $C$. The desolvation temperature of Me was determined by TGA-DSC-MS measurement. The incorporated $\mathrm{MeOH}$ molecules were released at $50.4{ }^{\circ} \mathrm{C}$, and Me turned to $\mathrm{C}$ and/or Rac depending on the heating rate. XRPD measurements confirmed that each phase could be prepared as a structurally pure phase (Figure 2).

Table 1. Thermochemical properties of the four solid phases of 1. C: $\{(+)$ and $(-)\}$, Rac, and Me.

\begin{tabular}{llll}
\hline & $\mathrm{C}$ & Rac & $\mathrm{Me}$ \\
\hline $\begin{array}{l}\text { Thermodynamic } \\
\text { stability }\end{array}$ & Stable & $\begin{array}{l}\text { Slowly transforms } \\
\text { to } \mathrm{C} \text { at high } \\
\text { temperature }\end{array}$ & $\begin{array}{l}\text { The surface can be } \\
\text { desolvated under } \\
\text { ambient condition }\end{array}$ \\
Melting point $/{ }^{\circ} \mathrm{C}$ & 111.2 & 99.4 & 50.4 \\
& & & desolvation
\end{tabular}

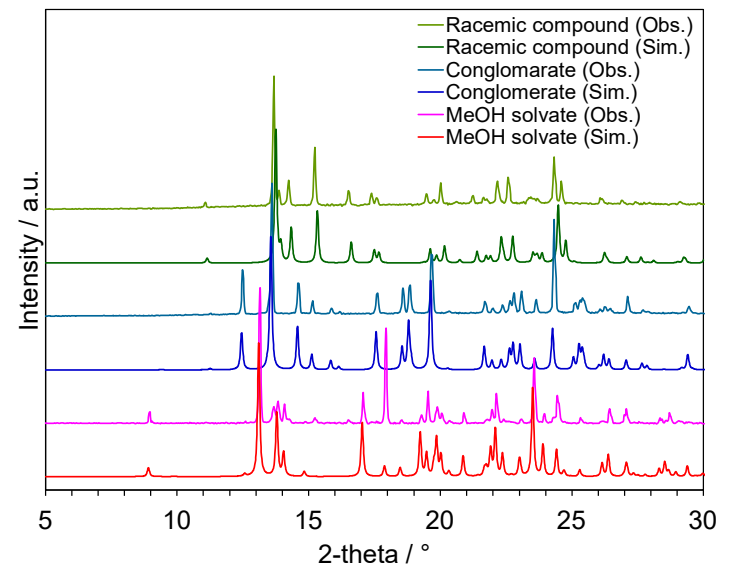

Figure 2. XRPD patterns of the three crystal forms of 1.

\subsection{Crystal structures of Rac and Me}

Crystallographic data for $\mathrm{C}$, Rac, and Me of 1 are summarized in Table 2 for comparison. The data for $C$ has been included from Sakamoto's report, ref code NATQEF. Rac and Me correspond to racemic compound. ORTEP representations of Rac and Me are shown in Figure $\mathbf{3 a}$ and $\mathbf{b}$, respectively. The overlaid molecular structures of Rac and Me (Figure 3c) indicate that the conformations in both solid phases are almost identical. By contrast, the major difference between Rac and $C$ was found in the piperidyl residues, as shown in Figure $\mathbf{3 d}$. In both solid phases, the piperidyl groups exist in the chair conformation. However, the conformation of the piperidine ring are opposite, with the two piperidyl rings related as flipped chairs.
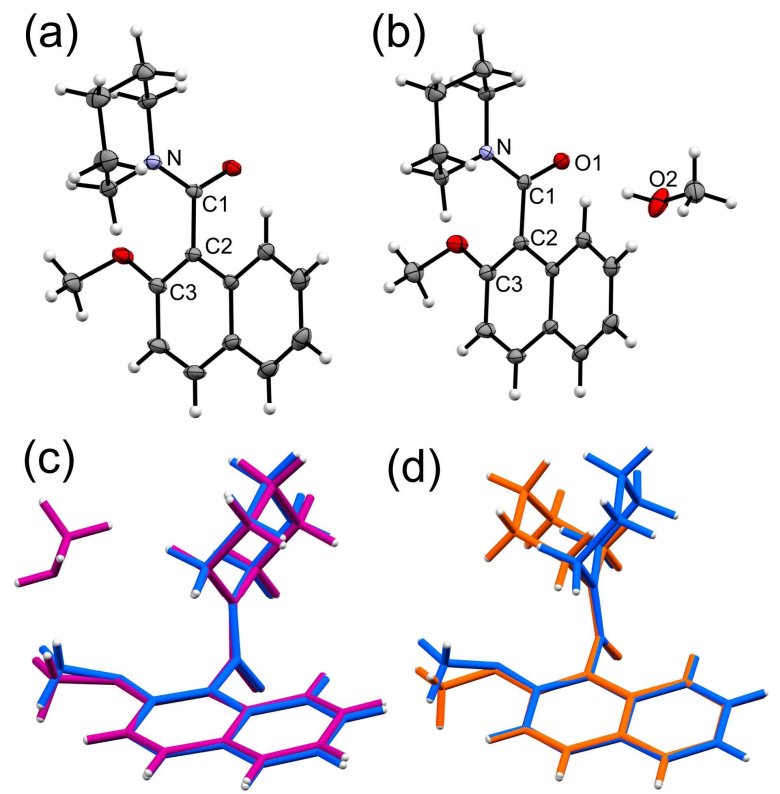

Figure 3. ORTEP representations of the $(R)$-enantiomer (a) in Rac, and (b) in Me of 1 at $150 \mathrm{~K}$. Thermal ellipsoids are displayed at $50 \%$ probability. Overlaid molecular structures in (c) Rac (blue) and Me (magenta), and (d) Rac (blue) and C (orange). 
Table 2. Crystallographic data of C, Rac, and Me.

\begin{tabular}{|c|c|c|c|}
\hline Name & $\mathrm{C}^{[\mathrm{a}]}$ & Rac & $\mathrm{Me}$ \\
\hline Chemical formula & $\mathrm{C}_{17} \mathrm{H}_{19} \mathrm{NO}_{2}$ & $\mathrm{C}_{17} \mathrm{H}_{19} \mathrm{NO}_{2}$ & $\mathrm{C}_{17} \mathrm{H}_{19} \mathrm{NO}_{2}, \mathrm{CH}_{4} \mathrm{O}$ \\
\hline Formula mass & 269.33 & 269.33 & 301.37 \\
\hline Crystal system & Orthorhombic & Monoclinic & Monoclinic \\
\hline a / $\AA$ & $7.963(3)$ & $8.8254(7)$ & $8.9139(8)$ \\
\hline$b / \AA$ & $11.713(3)$ & $18.3093(14)$ & $9.1407(7)$ \\
\hline$c / \AA$ & $15.708(4)$ & $9.0671(6)$ & $19.7111(16)$ \\
\hline$a 1^{\circ}$ & 90 & 90 & 90 \\
\hline$b /^{\circ}$ & 90 & $94.273(3)$ & $96.114(3)$ \\
\hline$g 1^{\circ}$ & 90 & 90 & 90 \\
\hline Unit cell volume / $\AA^{3}$ & $1465.2(8)$ & 1461.1(2) & $1596.9(2)$ \\
\hline Temperature / K & 298 & $150(2)$ & $150(2)$ \\
\hline Space group & $P 2{ }_{1} 2_{1} 2_{1}$ & $P 2{ }_{1} / \mathrm{c}$ & $P 2{ }_{1} / \mathrm{c}$ \\
\hline No. of formula units per cell, $Z$ & 4 & 4 & 4 \\
\hline No. of reflections measured & - & 107936 & 101718 \\
\hline No. of independent reflections & 1611 & 5612 & 6125 \\
\hline$R_{\text {int }}$ & - & 0.0624 & 0.0327 \\
\hline Final $R_{1}$ values $(I>2 s(l))$ & 0.0499 & 0.0495 & 0.0410 \\
\hline Final $\mathrm{w} R\left(F^{2}\right)$ values $(l>2 s(l))$ & 0.1316 & 0.1264 & 0.0503 \\
\hline Final $R_{1}$ values (all data) & - & 0.0756 & 0.1150 \\
\hline Final $w R\left(F^{2}\right)$ values (all data) & - & 0.1412 & 0.1222 \\
\hline Goodness of fit on $F^{2}$ & 1.125 & 1.024 & 1.060 \\
\hline
\end{tabular}

[a]Reported by Sakamoto et al. Ref code: NATQEF. (a) Rac

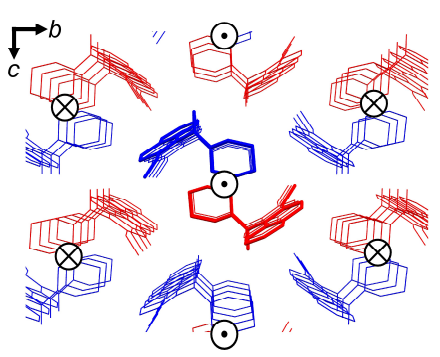

(b) $\mathrm{Me}$

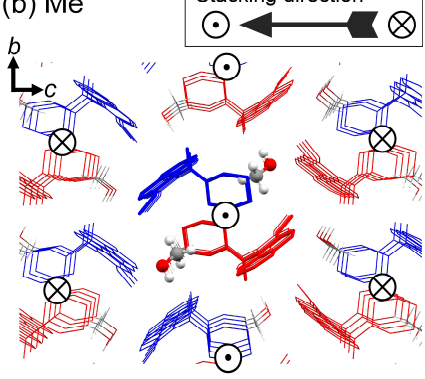

Figure 4. Crystal packing of (a) Rac and (b) Me along the a-axis. Hydrogen atoms are omitted for clarity. $R$ - and $S$ - isomers are colored in red and blue, respectively.

In Rac, the centrosymmetric pairs are stacked along the a-axis. Other columns with the same stacking direction are arranged in an ac plan, and the columns with opposite stacking direction are arranged in the next ac planes shifted by + and $-1 / 2 b$-axis (Figure 4a). In Me, the packing structure is basically the same as in Rac (Figure 4b). However, the differences between the Rac and $\mathrm{Me}$ are as follows: (i) the $\mathrm{MeOH}$ molecules are accommodated in the pocket next to the molecules of $\mathbf{1}$, and (ii) the direction of the stacked columns in the adjacent $a b$ plane is similar but the centrosymmetric pairs are swapped.

\subsection{Quaternary phase diagram of $R, S-1, \mathrm{MeOH}$, and water}

Since the quaternary equilibria of $\mathrm{MeOH}, \mathrm{H}_{2} \mathrm{O}$, and the enantiomers of 1 resulted in a complicated system due to the spontaneous racemization in solution, we briefly introduce the ternary systems relevant for the solid phases of $\mathbf{1}$. Figure 5 summarizes the ternary phase diagrams of the enantiomers of a chiral molecule with a solvent, both for the presence and absence of racemization in the solution. ${ }^{[17,23-25]}$ Any composition in the undersaturated or saturated solutions will evolve towards the racemic composition because of the racemization in the liquid phase. Many results have reported an irreversible evolution to a single chirality in the solid state for racemizable conglomerate forming systems. ${ }^{[8,26-29]}$ As long as the system remains an undersaturated solution, the enantiomeric excess of the system remains zero. However, once the conglomerate starts to crystallize, the system in equilibrium will consist of a racemic solution and a single chiral solid. In case of a racemic compound, only the racemic compound and a racemic solution are accessible for the system in equilibrium. Figure 6 depicts the schematic isothermal and isobaric quaternary system of $\mathrm{MeOH}, \mathrm{H}_{2} \mathrm{O}$, and the enantiomers of 1 . Every face of the tetrahedron represents a ternary isotherm. Compound $\mathbf{1}$ forms a stable $\mathrm{MeOH}$ solvate racemic compound in methanol and a stable conglomerate in water. Since compound 1 exhibits spontaneous racemization in any solution, the two conglomerate isotherms are degenerated. Regarding the racemic isoplethal section outlined in magenta lines, $( \pm)-1 / \mathrm{MeOH} / \mathrm{H}_{2} \mathrm{O}$, two cases were observed depending on the temperature as shown in Figure 7. Depending on the solvent composition, the following solid phases; C, Rac, and Me could be stable in the racemic isoplethal section, with Me being the stable phase at a high $\mathrm{MeOH}$ concentration, Rac being the stable phase at a moderate $\mathrm{MeOH}$ concentration, and $\mathrm{C}$ being the stable phases at low $\mathrm{MeOH}$ concentration. It is also surprising that regardless of the relative stability of $\mathrm{C}$ with Rac in the binary system, Rac is more stable phase than $\mathrm{C}$ at a moderate $\mathrm{MeOH}$ concentration at lower temperature. Indeed, C crystals were converted to Rac in such suspension, and cross-seeding experiments gave similar results. Point $\mathrm{H}$ indicates the solubility of $\mathrm{Me}$ in $\mathrm{MeOH}$. Point I is the common point in the solubility curves of $\mathrm{Me}$ and Rac, in case these two phases would have had a monotropic character point l' would have not existed in equilibrium. At point I', the intersection of the solubility curves of Rac and C, three solid phases co-exist before racemization occurs. Thus, measuring the point where the composition of the two phases does not change is a straightforward approach to confirm the existence of l'. We used XRPD measurements after crossseeding and continuous stirring for one week to confirm the presence of point l'. 


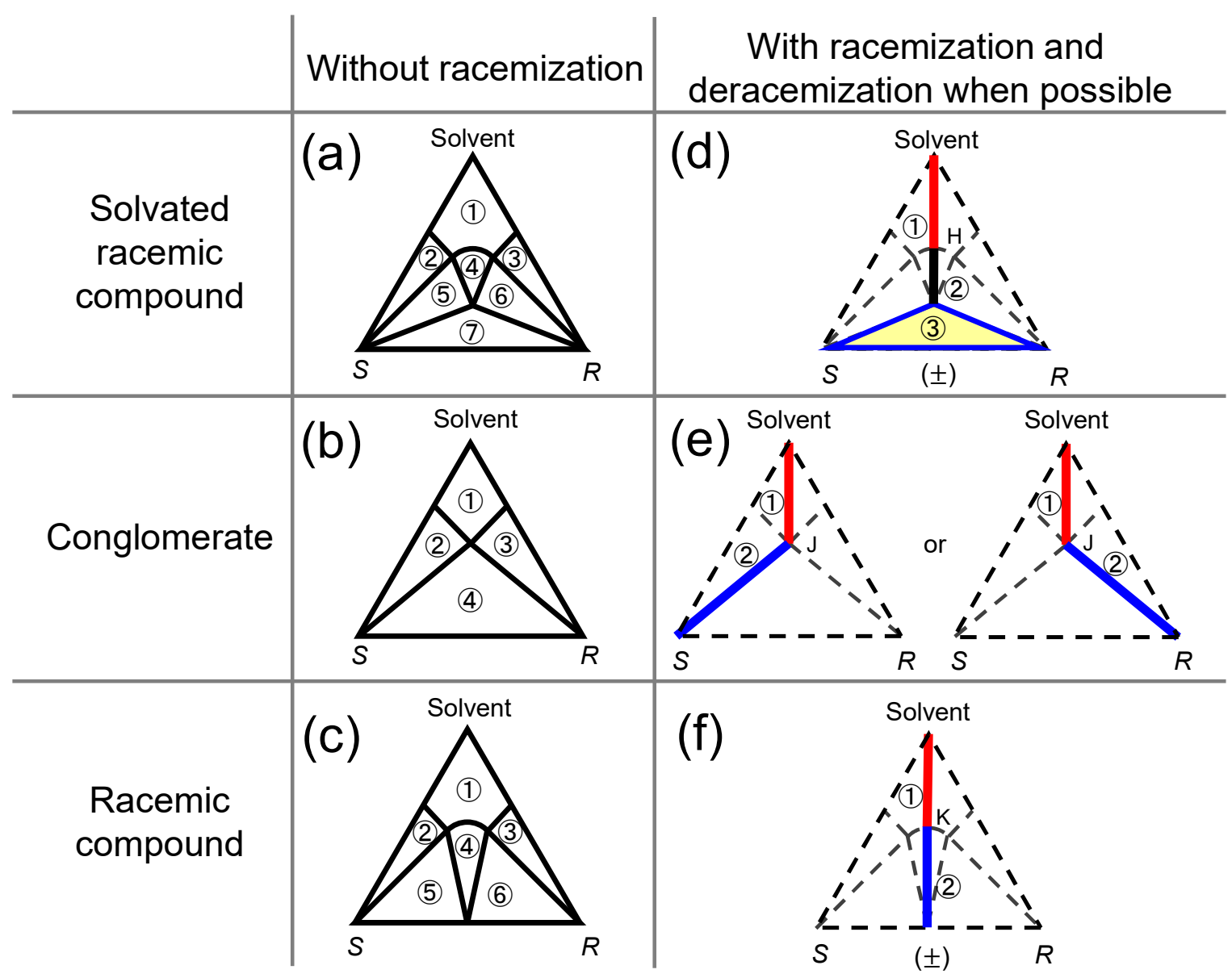

Figure 5. Ternary system of solvated racemic compound, conglomerate, and racemic compound and corresponding degenerated system due to the racemization in solution. Only domains limited by full lines are accessible. Deracemization is supposed to occur only when a stable conglomerate is in contact with a solution. The stable phases for the ternary system are : (a) (1) undersaturated solution; (2) $\langle\mathrm{S}\rangle+$ saturated solution; (3) $\langle\mathrm{R}\rangle+$ saturated solution; (4) $\langle( \pm) \cdot$ MeOH $\rangle+$ saturated solution; (5) $\langle( \pm) \cdot \mathrm{MeOH}\rangle+\langle\mathrm{S}\rangle+$ saturated solution; (6) $\langle( \pm) \cdot \mathrm{MeOH}\rangle+\langle\mathrm{R}\rangle+$ saturated solution; and $(7)\langle( \pm) \cdot \mathrm{MeOH}\rangle+\langle\mathrm{S}\rangle+\langle\mathrm{R}\rangle$, (b) (1) undersaturated solution; (2) $\langle\mathrm{S}\rangle+$ saturated solution; (3) $\langle R\rangle+$ saturated solution; and (4) $\langle\mathrm{S}\rangle+\langle\mathrm{R}\rangle+$ racemic saturated solution, (c) (1) undersaturated solution; (2) $\langle\mathrm{S}\rangle+$ saturated solution; (3) $\langle\mathrm{R}\rangle+$ saturated solution; (4) $\langle( \pm)\rangle+$ saturated solution; (5) $\langle\mathrm{S}\rangle+\langle( \pm)\rangle+$ doubly saturated solution; and (6) $\langle\mathrm{R}\rangle+\langle( \pm)\rangle+$ doubly saturated solution. The stable phases for the degenerated ternary equilibrium are: (d) (1) undersaturated solution; (2) $\langle( \pm) \cdot \mathrm{MeOH}\rangle+$ racemic saturated solution $\mathrm{H}$; (3) $\langle( \pm) \cdot \mathrm{MeOH}\rangle+\langle\mathrm{S}\rangle+\langle\mathrm{R}\rangle$, (e) (1) undersaturated solution; (2) $\langle\mathrm{S}\rangle$ or $\langle\mathrm{R}\rangle+$ racemic saturated solution J, (f) (1) undersaturated solution; (2) $\langle( \pm)\rangle+$ racemic saturated solution $\mathrm{K}$.

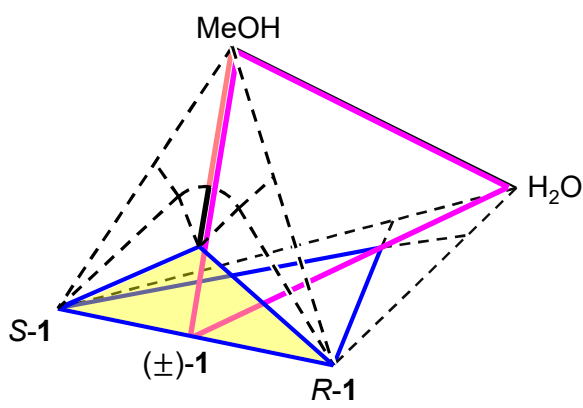

Figure 6. Quaternary isotherm system with a couple of enantiomers of $1, \mathrm{MeOH}$ and $\mathrm{H}_{2} \mathrm{O}$. The triangular face $(\mathrm{MeOH} / \mathrm{S}-1 / R-1)$ represents the ternary isotherm indicating a stable solvated racemic compound with racemization. The base of the tetrahedron corresponds to the ternary isotherm $\left(\mathrm{H}_{2} \mathrm{O} / \mathrm{S}-1 / R-1\right)$ showing the stable conglomerate with racemization. Magenta triangular plane is the racemic isoplethal section, ( \pm )-1/MeOH/ $\mathrm{H}_{2} \mathrm{O}$.
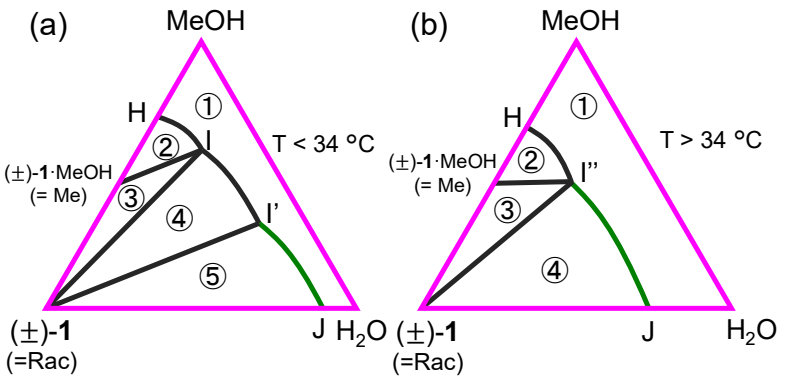

Figure 7. The ternary equilibrium at the racemic isoplethal section of $( \pm)-$ $1 / \mathrm{MeOH} / \mathrm{H}_{2} \mathrm{O}$ (a) below $34{ }^{\circ} \mathrm{C}$ (1) unsaturated solution; (2) $\langle( \pm)-1 \cdot \mathrm{MeOH}\rangle+$ saturated solution; (3) $\langle( \pm)-1\rangle+\langle( \pm)-1 \cdot \mathrm{MeOH}\rangle$ doubly saturated solution I; and (4) $\langle( \pm)-1\rangle+$ saturated solution; (5) $\langle(+)-1\rangle+\langle(-)-1\rangle+$ saturated solution, and (b) above $34{ }^{\circ} \mathrm{C}$ (1) unsaturated solution; (2) $\langle( \pm)-\mathbf{1} \cdot \mathrm{MeOH}\rangle+$ saturated solution; (3) $\langle(+)-1\rangle+\langle(-)-1\rangle+\langle( \pm)-1 \cdot \mathrm{MeOH}\rangle$ triply saturated solution I"; and (4) $\langle(+)-1\rangle+\langle(-)-$ $1\rangle+$ saturated solution. Every solution has a racemic composition. 


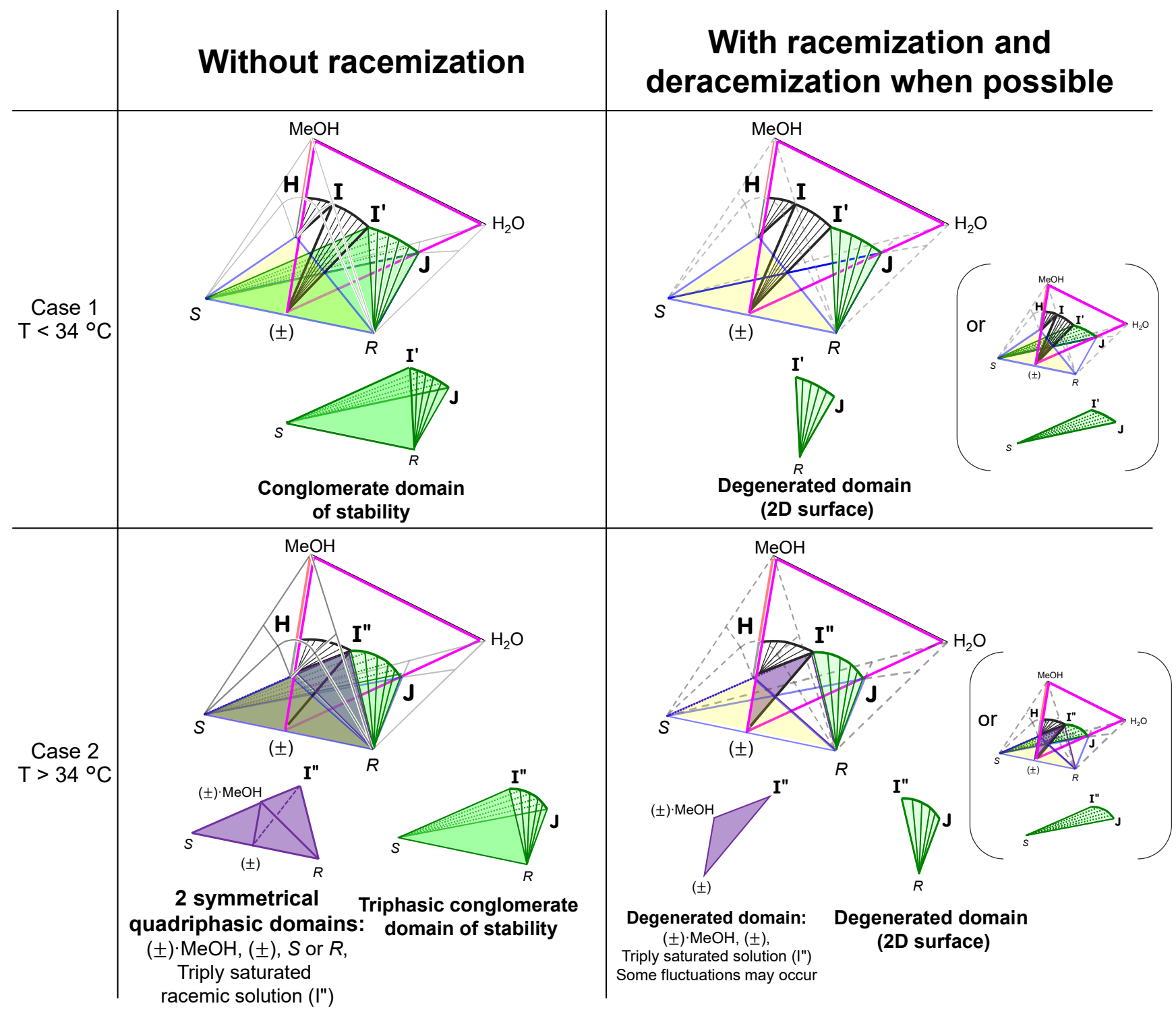

Figure 8. Quaternary system with two different solvents $\left(\mathrm{MeOH}\right.$, and $\left.\mathrm{H}_{2} \mathrm{O}\right)$, and a couple of enantiomers $(R$ and $S)$ with and without racemization in the liquid phase with two types of racemic isoplethal section shown in Figure 6 . The systems with racemization correspond to the $( \pm)-1 / \mathrm{MeOH} / \mathrm{H}_{2} \mathrm{O}$. In $\mathrm{Case} 1$, the curves in the racemic isoplethal section $(\mathrm{H}-\mathrm{I}, \mathrm{I}-\mathrm{l}$ ', I' $-\mathrm{J}$ ) correspond to the solubility curves of Me, Rac, and $\mathrm{C}$, respectively. When deracemization occurs, conglomerate domain of stability degenerates to a $2 \mathrm{D}$ surface involving one of the enantiomers and the racemic compound ( \pm ), as coloured in green. In addition, the domain in the ternary system $(\mathrm{MeOH} / R / S)$ is also involved in the equilibrium. In Case 2, the solubility lines in the racemic isoplethal section $(\mathrm{H}-\mathrm{I}$ " and I" - J) correspond to the solubility curves of Me and C, respectively. In contrast to Case 1, the conglomerate domain of stability does not include racemic compound ( \pm ). Only domains limited by full lines are accessible.

Figure 8 summarizes isothermal and isobaric quaternary systems with and without racemization. The domains highlighted in green or purple represent the areas of chiral discrimination, i.e., these domains involve conglomerate forms. Another similar case was described in detail in a review. ${ }^{[30]}$ Under the usual condition without racemization in Case 1, the upper surface of conglomerate stability domain is delineated by the $S-R-$ l' plane it contains the racemic compound $( \pm)$. In Case 2 without deracemization, the two symmetrical quadriphasic domains related to racemic plane are delineated by the line from the common point I" and the stoichiometric point of $( \pm) \cdot \mathrm{MeOH}$.
Beyond point l", toward richer concentration in water, there is a single monovarient curve down to the doubly saturated solubility point $\mathrm{J}$ in pure $\mathrm{H}_{2} \mathrm{O}$, that represents the edge of the conglomerate domain of the stability. Conversely, in case of deracemization conglomerate, the crystals of a single enantiomer and racemic solution are in equilibrium at the end of the deracemization as described above. Thus, both cases 1 and 2 are degenerated and should be drawn by the system as shown in the right column of Figure 8. For enthusiastic readers, the animated perspectives are available in Supporting Information. 
(a) $( \pm)-1$

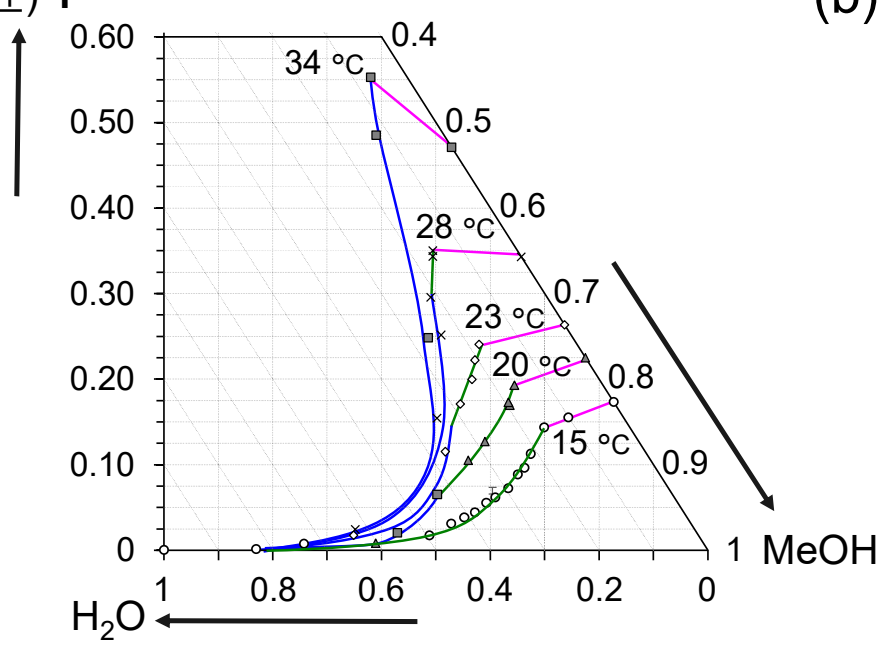

(b) Temp.

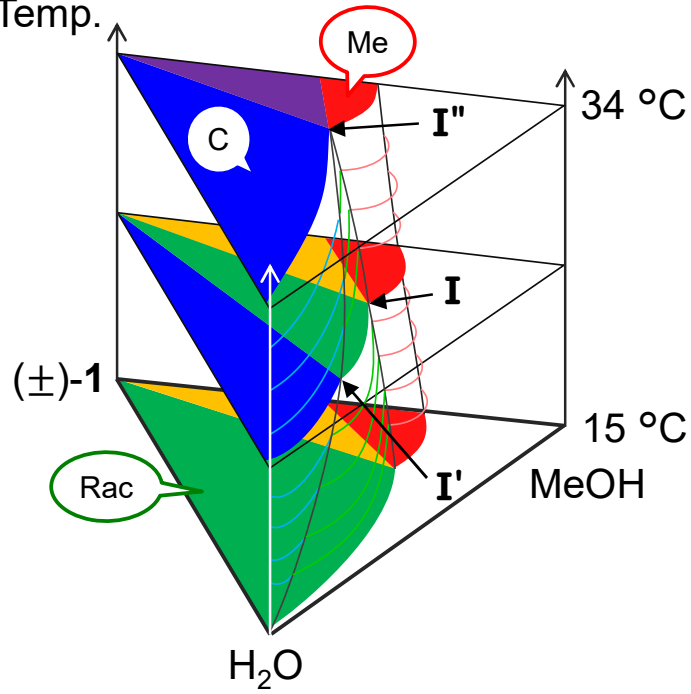

Figure 9. (a) The isoplethal sections of the quaternary phase diagrams of $(R)$ - and $(S)$-enantiomers of $1, \mathrm{H}_{2} \mathrm{O}$, and $\mathrm{MeOH}$ at $15^{\circ} \mathrm{C}(\circ), 20^{\circ} \mathrm{C}(\boldsymbol{\Delta}), 23^{\circ} \mathrm{C}(\diamond), 28^{\circ} \mathrm{C}$ $(\times)$, and $34^{\circ} \mathrm{C}(\mathbf{m})$. (b) Schematic diagram of the isoplethal section along the temperature axis.

To understand the concrete heterogeneous equilibrium at different temperatures, we studied the isoplethal sections of $( \pm)$ $1 / \mathrm{MeOH} / \mathrm{H}_{2} \mathrm{O}$ at $15,20,23,28$, and $34{ }^{\circ} \mathrm{C}$. Interestingly, Rac under ambient conditions has a large stability domain at $15^{\circ} \mathrm{C}$ at high water concentration, as seen from Figure 9. Further, the domain of stable $\mathrm{C}$ gradually expands at higher temperature. Point I' exists at relatively high concentrations of $\mathrm{H}_{2} \mathrm{O}$ at low temperatures, and shifts towards low concentrations of $\mathrm{H}_{2} \mathrm{O}$ at high temperatures. While the size of the domain for Me does not change significantly, point I remains at almost the same composition. As a result, points I' and I merged into I" at $34{ }^{\circ} \mathrm{C}$, and the domain of stable Rac disappears, indicating that Rac is no longer stable above $34{ }^{\circ} \mathrm{C}$. Since Me desolvated at $50{ }^{\circ} \mathrm{C}$ and cannot exist above such temperature, the size of the domain of stable $\mathrm{C}$ expands in a two-step manner up to $50^{\circ} \mathrm{C}$.

Overall, the thorough phase diagram study afforded guidelines for the chiral separation of $\mathbf{1}$ by crystallization. As the conglomerateforming system is necessary, the chiral separation could be ideally implemented above $34^{\circ} \mathrm{C}$. Considering the solubility of $\mathbf{1}$, the chiral separation of 1 was carried out in $\mathrm{MeOH} / \mathrm{H}_{2} \mathrm{O}(70 / 30$, $\mathrm{v} / \mathrm{v}$ ) above $28^{\circ} \mathrm{C}$, and at this solvent composition, $\mathrm{C}$ is stable, and its solubility is moderate at this operating temperature.

\subsection{Deracemization by SOAT}

To confirm racemization of $\mathbf{1}$ in solution, and to implement deracemization by SOAT, the kinetic constants $k_{1}$ for the racemization process were measured by polarimetry at a temperature range from 15 to $45^{\circ} \mathrm{C}$. The values were used to construct an Arrhenius plot. ${ }^{[16]}$ The Gibbs free energy of activation $\left(\Delta G^{\ddagger}\right)$ was determined to be $96 \mathrm{~kJ} \cdot \mathrm{mol}^{-1}$ (See Supporting Information). The racemization rate was slower in polar solvents compared to non-polar solvents, and particularly in protic solvents such as $\mathrm{MeOH}$ and a mixture of $\mathrm{MeOH} / \mathrm{H}_{2} \mathrm{O}(70 / 30$, v/v). This behavior is similar to a pyrrolidine, and the observations can be attributed to hydrogen bonding between the carbonyl oxygen atom of 1 and the solvent, which reduces the rate of racemization. Generally, a slow racemization of the molecule during the deracemization process is not preferred as the enantiomeric composition in the solution during the crystallization would gradually shift in the direction of the undesired enantiomer, which could eventually cause nucleation of the counter-enantiomer due to the relatively high supersaturation, as shown in Figure 10. In this context, the deracemization of 1 in a mixture of $\mathrm{MeOH} / \mathrm{H}_{2} \mathrm{O}$ $(70 / 30, v / v)$ would not be preferable. Further screening test might give a solution to such a problematic case. However, considering the feasibility of SOAT, a too high or poor solubility was trade-off problem by considering $\mathrm{MeOH}$ mixtures. Thus, we used the mixture of $\mathrm{MeOH}$ and $\mathrm{H}_{2} \mathrm{O}$ with optimization of the crystallization duration, because the behavior of $\mathbf{1}$ had been well studied as abovementioned.

The results of the SOAT of 1 are summarized in Table 3 . As expected from the racemization behavior of 1 , the short crystallization duration of $10 \mathrm{~h}$ resulted in a low ee of the isolated crystals. The crystallization duration of $20 \mathrm{~h}$ furnished high ee with a maximum of $97 \%$ ee. To confirm the reproducibility of the experiment, we performed SOAT with the same duration and used seed crystals of the opposite enantiomer, which afforded a good ee after $20 \mathrm{~h}$ with an average value of $90 \%$ ee. The average volumetric productivity, ${ }^{[32]}$ which indicates the quantity of the desired product that can be obtained per time unit and volume was $6.5 \mathrm{~g} \mathrm{~h}^{-1} \mathrm{~L}^{-1}$ for the process. Compared to our previous study, ${ }^{[16]}$ which demonstrated a comparison of productivity between SOAT and TCID, the productivity in the present work is low owing to the long crystallization duration caused by the poor racemization rate. 


\section{(a) Fast racemization}

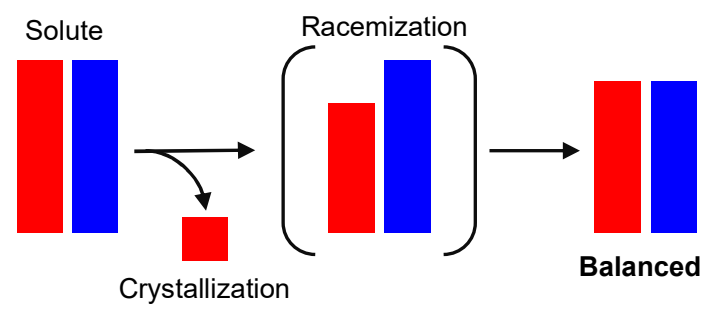

(b) Slow racemization

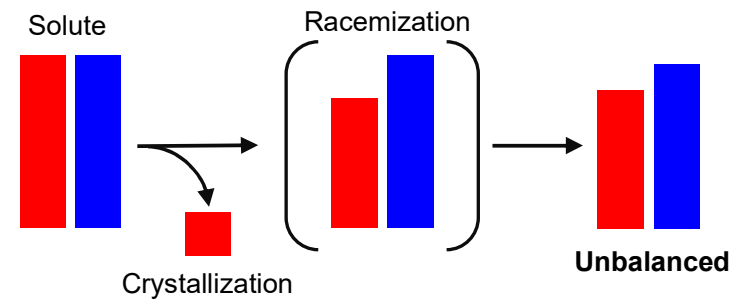

Time

Figure 10. Schematic representation of the chiral separation by crystallization with (a) fast racemization and (b) slow racemization.

Table 3. Experimental results of SOAT of 1 in $\mathrm{MeOH} / \mathrm{H}_{2} \mathrm{O}(70 / 30, \mathrm{v} / \mathrm{v})$.

\begin{tabular}{cccc}
\hline Duration $/ \mathrm{h}$ & $m_{\text {crop }} / \mathrm{g}$ & $\mathrm{ee}_{\text {final }}[\%]$ & $\mathrm{Pr} / \mathrm{g} \mathrm{h}^{-1} \mathrm{~L}^{-1}$ \\
\hline 10 & 16.5 & $(S) 11$ & 0.9 \\
15 & 14.7 & $(S) 68$ & 6.0 \\
\hline 20 & 16.1 & $(S) 97$ & 7.3 \\
20 & 15.4 & $(R) 92$ & 6.6 \\
20 & 14.9 & $(R) 81$ & 5.5 \\
\hline
\end{tabular}

\section{Conclusions}

The crystal structures of a racemic compound (Rac) and a racemic compound methanol solvate $(\mathrm{Me})$ of axially chiral naphthamide 1 have been determined. The quaternary phase diagram of enantiomers of 1 in $\mathrm{MeOH}$ and $\mathrm{H}_{2} \mathrm{O}$ has been constructed. Particularly, the impact of temperature on the racemic isoplethal section of $\mathbf{1}$ in solution was thoroughly studied over a temperature range from 15 to $34{ }^{\circ} \mathrm{C}$. At $15{ }^{\circ} \mathrm{C}$, Rac is a stable phase in high $\mathrm{H}_{2} \mathrm{O}$ concentration, while Me was stable at a low $\mathrm{H}_{2} \mathrm{O}$ concentration. The domain for the stable $\mathrm{C}$ gradually expands from a high $\mathrm{H}_{2} \mathrm{O}$ concentration region with increasing temperature. Eventually, the domain for Rac disappears at $34^{\circ} \mathrm{C}$, and only $\mathrm{C}$ and $\mathrm{Me}$ are stable up to $50^{\circ} \mathrm{C}$. Based on the phase diagram study, it is demonstrated that the chiral separation of the enantiomers of 1 by SOAT in $\mathrm{MeOH} / \mathrm{H}_{2} \mathrm{O}(70 / 30, \mathrm{v} / \mathrm{v})$, resulted in crystals with high enantiomeric excess (up to $97 \%$ ee). These results further prove the efficiency of the phase diagram approach for enabling chiral separation by crystallization even when there is a stable racemic compound forming system which is typically challenging. The lessons from the present study will serve as a model for developing deracemization applications for industrial processes.

\section{Experimental Section}

Synthesis of 1 and preparation of C, Rac, and Me

Naphthamide 1 was synthesized using our previously reported procedure, ${ }^{[10]}$ with a slight modification. The conversion of 2-hydroxy-1naphthoic acid (Sigma-Aldrich) to 2-methoxy-1-naphthoic acid was carried out in 2 steps, and the condensation of the prepared 2-methoxy naphthoic acid with piperidine afforded 1 . The methods for the preparation of the conglomerate $(\mathrm{C})$, racemic compound (Rac), and $\mathrm{MeOH}$ solvate racemic compound (Me) are summarized in Table 4.

Table 4. Preparation methods for the three solid phases of 1.

\begin{tabular}{|c|c|}
\hline Solid phase & Preparation method \\
\hline $\mathrm{C}$ & Slow evaporation from conventional solvents ${ }^{[a]}$ \\
\hline Rac & $\begin{array}{c}\text { Cooling crystallization from } \mathrm{CHCl}_{3} / \mathrm{Heptane}(1 / 1 \\
\text { v/v) mixture or slow evaporation from a } \mathrm{MeOH} / \mathrm{H}_{2} \\
(8 / 2, \mathrm{v} / \mathrm{v}) \text { mixture }\end{array}$ \\
\hline $\mathrm{Me}$ & $\begin{array}{c}\text { Cooling crystallization or slow evaporation } \\
\text { from a solution in } \mathrm{MeOH}\end{array}$ \\
\hline
\end{tabular}

[a]Ethanol, Isopropyl alcohol, tert-Butyl alcohol, Acetonitrile, Isobutyronitrile, Methyl tert-butyl ether, Tetrahydrofuran, Acetone, and Methyl iso-butyl ketone

\section{Chiral HPLC analysis}

The accurate chiral composition of 1 in solid samples (powder or single crystals) was determined by using high-performance liquid chromatography (HPLC) with an $(S, S)$ Whelk-O1 column (Regis Technologies, Inc., $\varphi 4.6 \times 250 \mathrm{~mm} \times 5 \mu \mathrm{m})$ employing a mixture of heptane and isopropyl alcohol $(1 / 1, \mathrm{v} / \mathrm{v})$ as the mobile phase, at a flow rate of $1.5 \mathrm{~mL} / \mathrm{min}$. The wavelength employed for UV detection was $230 \mathrm{~nm}$. To suppress racemization during analysis, the column temperature was controlled at $0{ }^{\circ} \mathrm{C}$ using a thermostat with a double glass jacket. Under these conditions, retention times of 3.8 and 5.5 min were observed for $(R)$ 1 and (S)-1, respectively. Analyses were performed using a SpectraSYSTEM (P1000XR, AS3000, UV2000, and SN4000, and Fisher Thermo Scientific). The enantiomeric excess (ee) values were obtained by integrating and comparing the peak areas of $(R)-1$ and $(S)-1$ using ChromQuest software.

\section{Differential Scanning Calorimetry (DSC)}

DSC experiments were performed using a Netzsch DSC 204 F1 apparatus equipped with an intracooler. Each DSC run was completed in aluminum pans with pierced lids at a heating rate of $5.0 \mathrm{~K} / \mathrm{min}$. The atmosphere of the analytes during the analysis was regulated by a nitrogen flux (40 $\mathrm{mL} / \mathrm{min}$ ), and Netzsch-TA Proteus software was used for data processing. Onset temperatures used as the melting point or desolvation point were calculated from the intersection between the baseline and the slope of the first (respectively last) portion of the endotherm. 


\section{Single Crystal X-ray Diffraction (SC-XRD)}

Reflections were measured on a Bruker D8 Quest diffractometer with a sealed tube, and a Triumph monochromator $(\lambda=0.71073 \AA)$ and the intensity integration was carried out using the software Saint. Absorption correction was performed with SADABS. The structures were solved with direct methods using SHELXT. ${ }^{[33]}$ Least-squares refinement was performed with SHELXL-2014 ${ }^{[34]}$ against all reflections. Non-hydrogen atoms were refined freely with anisotropic displacement parameters. The positions of the hydrogen atoms were calculated or located by differences in Fourier maps. All hydrogen atoms were refined with a riding model. Copies of the data can be obtained free of charge on application to CCDC, 12 Union Road, Cambridge CB2 1EW, U.K. (deposit@ccdc.cam.ac.uk). CCDC 1936797, 1936798, and 1937666 .

\section{Solubility Measurements for the construction of the phase diagram}

The solubility of 1 in $\mathrm{MeOH}$ and in the mixture of $\mathrm{MeOH}$ and $\mathrm{H}_{2} \mathrm{O}$ was measured in triplicate using a gravimetric method or by the determination of clear point using Crystal16 (Technobis B.V.). The identity of the solid phase(s) in equilibrium with a saturated solution was monitored by XRPD analysis. To be sure of the stable character of a solid phase in certain composition of the solution, the sample for the solubility measurement was prepared by cross-seeding technique, i.e., the mixture of different forms of crystals was added in the clear saturated solution at the given temperature, and a long elapsed time before sampling the solution and analysis by XRPD of the solid phases.

\section{Second order asymmetric transformation (SOAT)}

SOAT of 1 was carried out according to the following procedure. To a double jacketed $100 \mathrm{~mL}$ crystallizer (Reactor-Ready Lab reactor, Radleys) equipped with a thermocouple and a mechanical stirrer, compound 1 and $\mathrm{MeOH} / \mathrm{H}_{2} \mathrm{O}\left(70 / 30\right.$, v/v) were added, and the mixture was heated to $50{ }^{\circ} \mathrm{C}$ with stirring (500 rpm) to dissolve 1 completely. The jacket temperature was controlled using a thermostat (Unichiller, HUBER). The solution was cooled to $34^{\circ} \mathrm{C}$ at a rate of $1 \mathrm{~K} \cdot \mathrm{min}^{-1}$, and the temperature was maintained for $20 \mathrm{~min}$. The seed crystals (>99\% ee of $R$ or $S$ isomer) were added to the solution at a stirring rate of $200 \mathrm{rpm}$, and the solution was cooled to $28^{\circ} \mathrm{C}$ with a controlled cooling profile. Typically, the optimization of cooling curves for different operating conditions is complex. However, Mullin et al. reported the simplified relationship depicted by Eq. 1, which is adequate for general applications. ${ }^{[35]}$

$$
\theta_{t}=\theta_{0}-\left(\theta_{0}-\theta_{\mathrm{f}}\right)(t / \tau)^{3} \quad(\text { Eq. } 1)
$$

Where $\theta_{0}, \theta_{\mathrm{f}}$, and $\theta_{t}$ are the temperatures at the beginning, end, and any time $t$ during the crystallization, respectively, and $\tau$ is the overall duration of the crystallization. Details of the operating conditions are summarized in Table 5

Table 5. Operating conditions for SOAT of 1

\begin{tabular}{lc}
\hline Mass of $1(\mathrm{~g})$ & 28.2 \\
Mass of solvent $(\mathrm{g})$ & 85.4 \\
Concentration $(\mathrm{wt} \%)$ & 24.8 \\
Mass of seeds $(\mathrm{g})$ & 1.00 \\
Stirring speed $(\mathrm{rpm})$ & 200 \\
Duration $(\mathrm{h})$ & $10,15,20$ \\
\hline
\end{tabular}

\section{Acknowledgements}

The authors are grateful to Prof. Dr. Lucia Maini in University of Bologna for single crystal X-ray diffraction measurement of Rac at $293 \mathrm{~K}$. This research received funding as part of a CORE project (October 2016-September 2020) from the Horizon 2020 Research and Innovation Programme of the European Union under Marie Sklodowska-Curie grant agreement No. 722456 CORE ITN. F.M. and Y.G. would like to thank Erasmus+ Programme of the European Union for the opportunity to carry out this project.

Keywords: Deracemization $\cdot$ Second-order asymmetric transformation $(\mathrm{SOAT}) \cdot$ Phase diagram $•$ Atropisomerism

[1] FDA's Center for Drug Evaluation and Research's (CDER's) Advancing health through innovation 2018 New drug therapy approvals, 2019

[2] B. G. de la Torre, F. Albericio, Molecules 2019, 24, 809

[3] P. H. Karpinski, Chem. Eng. Technol. 2006, 29, 233-237.

[4] S. L. Veinberg, K. E. Johnston, M. J. Jaroszewicz, B. M. Kispal, C. R. Mireault, T. Kobayashi, M. Pruski, R. W. Schurko, Phys. Chem. Chem. Phys. 2016, 18, 17713-17730.

[5] A. H. J. Engwerda, N. Koning, P. Tinnemans, H. Meekes, F. M. Bickelhaupt, F. P. J. T. Rutjes, E. Vlieg, Cryst. Growth Des. 2017, 17, 4454-4457.

[6] L. Spix, A. Alfring, H. Meekes, W. J. P. Van Enckevort, E. Vlieg Cryst. Growth Des. 2014, 14, 1744-1748.

[7] L. Spix, H. Meekes, R. H. Blaauw, W. J. P. Van Enckevort, E. Vlieg, Cryst. Growth Des. 2012, 12, 5796-5799.

[8] R. R. E. Steendam, J. Dickhout, W. J. P. Van Enckevort, H. Meekes, J. Raap, F. P. J. T. Rutjes, E. Vlieg, Cryst. Growth Des. 2015, 15, 1975-1982.

[9] W. L. Noorduin, P. Van Der Asdonk, A. A. C. Bode, H. Meekes, W. J. P. Van Enckevort, E. Vlieg, B. Kaptein, M. W. Van Der Meijden, R. M. Kellogg, G. Deroover, Org. Process Res. Dev. 2010, 14, 908 911.

[10] R. Oketani, M. Hoquante, C. Brandel, P. Cardinael, G. Coquerel, Cryst. Growth Des. 2018, 18, 6417-6420.

[11] K. Suwannasang, A. E. Flood, C. Rougeot, G. Coquerel, Org. Process Res. Dev. 2017, 21, 623-630.

[12] G. Belletti, H. Meekes, F. P. J. T. Rutjes, E. Vlieg, Cryst. Growth Des. 2018, acs.cgd.8b00856.

[13] C. Rougeot, F. Guillen, J. C. Plaquevent, G. Coquerel, Cryst. Growth Des. 2015, 15, 2151-2155.

[14] F. Breveglieri, G. M. Maggioni, M. Mazzotti, Cryst. Growth Des. 2018, 18, 1873-1881.

[15] A. A. Fytopoulos, C. Xiouras, M. E. Kavousanakis, T. Van Gerven, A. G. Boudouvis, G. D. Stefanidis, Cryst. Growth Des. 2018, acs.cgd.8b00706.

[16] R. Oketani, M. Hoquante, C. Brandel, P. Cardinael, G. Coquerel, Org. Process Res. Dev. 2019, acs.oprd.9b00133.

[17] G. Coquerel, in Polymorph. Pharm. Ind., Wiley-VCH Verlag GmbH \& Co. KGaA, Weinheim, Germany, 2018, pp. 91-132. 
Ed. 2008, 47, 6445-6447.

[19] E. Temmel, M. J. Eicke, F. Cascella, A. Seidel-Morgenstern, H. Lorenz, Cryst. Growth Des. 2019, 19, acs.cgd.8b01660.

[20] C. Brandel, Y. Amharar, J. M. Rollinger, U. J. Griesser, Y. Cartigny, S. Petit, G. Coquerel, Mol. Pharm. 2013, 10, 3850-61.

[21] J. Jacques, A. Collet, S. H. Wilen, Enantiomers, Racemates, and Resolutions, Wiley, 1981.

[22] M. Sakamoto, A. Unosawa, S. Kobaru, A. Saito, T. Mino, T. Fujita, Angew. Chem. Int. Ed. 2005, 44, 5523-5526.

[23] G. Coquerel, in Adv. Org. Cryst. Chem. (Eds.: R. Tamura, M. Miyata), Springer Japan, Tokyo, 2015, pp. 393-420.

[24] G. Coquerel, J. Pharm. Pharmacol. 2015, 67, 869-878.

[25] S. Gonella, G. Levilain, G. Coquerel, J. Therm. Anal. Calorim. 2011 103, 125-129.

W. L. Noorduin, B. Kaptein, H. Meekes, W. J. P. Van Enckevort, R. M. Kellogg, E. Vlieg, Angew. Chem. Int. Ed. 2009, 48, 4581-4583.

29] A. H. J. Engwerda, P. van Schayik, H. Jagtenberg, H. Meekes, F. P. J. T. Rutjes, E. Vlieg, Chem. - A Eur. J. 2018, 24, 2863-2867.

Coquerel, Chem. Soc. Rev. 2014, 43, 2286-300.

[31] M. Sakamoto, A. Unosawa, S. Kobaru, K. Fujita, T. Mino, T. Fujita, Chem. Commun. 2007, 3586.

[32] C. Rougeot, J. E. Hein, Org. Process Res. Dev. 2015, 19, 18091819.

[33] G. M. Sheldrick, Acta Crystallogr. Sect. A Found. Adv. 2015, 71, 38.

[34] G. M. Sheldrick, Acta Crystallogr. Sect. C Struct. Chem. 2015, 71, 3-8.

[35] J. W. Mullin, Crystallization, Butterworth Heinemann, Oxford, 2001.

[26] C. Viedma, J. Cryst. Growth 2004, 261, 118-121.

[27] W. L. Noorduin, H. Meekes, W. J. P. Van Enckevort, A. Millemaggi, M. Leeman, B. Kaptein, R. M. Kellogg, E. Vlieg, Angew. Chem. Int. 